\title{
Accounting for the effects of sastrugi in the CERES clear-sky Antarctic shortwave angular distribution models
}

\author{
J. Corbett ${ }^{1}$ and W. Su ${ }^{2}$ \\ ${ }^{1}$ Science Systems and Applications, Inc., NASA Langley Research Center, Mail Stop 420, Hampton, \\ Virginia 23681-2199, USA \\ ${ }^{2}$ NASA Langley Research Center, Mail Stop 420, Hampton, Virginia 23681-2199, USA \\ Correspondence to: J. Corbett (joseph.g.corbett@nasa.gov)
}

Received: 20 November 2014 - Published in Atmos. Meas. Tech. Discuss.: 12 January 2015

Revised: 25 June 2015 - Accepted: 23 July 2015 - Published: 10 August 2015

\begin{abstract}
The Cloud and the Earth's Radiant Energy System (CERES) instruments on NASA's Terra, Aqua and Soumi NPP satellites are used to provide a long-term measurement of Earth's energy budget. To accomplish this, the radiances measured by the instruments must be inverted to fluxes by the use of a scene-type-dependent angular distribution model (ADM). For permanent snow scenes over Antarctica, shortwave (SW) ADMs are created by compositing radiance measurements over the full viewing zenith and azimuth range. However, the presence of small-scale wind blown roughness features called sastrugi cause the BRDF (bidirectional reflectance distribution function) of the snow to vary significantly based upon the solar azimuth angle and location. This can result in monthly regional biases between -12 and $7.5 \mathrm{Wm}^{-2}$ in the inverted TOA (top-of-atmosphere) SW flux. The bias is assessed by comparing the CERES shortwave fluxes derived from nadir observations with those from all viewing zenith angles, as the sastrugi affect fluxes inverted from the oblique viewing angles more than for the nadir viewing angles. In this paper we further describe the clearsky Antarctic ADMs from Su et al. (2015). These ADMs account for the sastrugi effect by using measurements from the Multi-Angle Imaging Spectro-Radiometer (MISR) instrument to derive statistical relationships between radiance from different viewing angles. We show here that these ADMs reduce the bias and artifacts in the CERES SW flux caused by sastrugi, both locally and Antarctic-wide. The regional monthly biases from sastrugi are reduced to between -5 and $7 \mathrm{Wm}^{-2}$, and the monthly-mean biases over Antarctica are reduced by up to $0.64 \mathrm{Wm}^{-2}$, a decrease of $74 \%$. These im-
\end{abstract}

proved ADMs are used as part of the Edition 4 CERES SSF (Single Scanner Footprint) data.

\section{Introduction}

The Clouds and the Earth's Radiant Energy System (CERES) instruments are used to estimate the amount of reflected shortwave (SW) flux and emitted longwave (LW) flux at the top of the atmosphere (TOA) (Wielicki et al., 1996). These fluxes are widely used in studies of Earth's energy budget. However, CERES measures radiances (in $\mathrm{Wm}^{-2} \mathrm{sr}^{-1}$ ) not flux (in $\mathrm{Wm}^{-2}$ ). In order to derive the flux from the radiance we use scene-dependent angular distribution models (ADMs) (Loeb et al., 2005). ADMs relate the reflected radiance at a given satellite viewing geometry to the total reflected flux. The viewing geometry is described in terms of satellite viewing zenith angle, $\theta_{v}$, the solar zenith angle, $\theta_{0}$ and the relative azimuth angle, $\phi=\phi_{v}-\phi_{0}$, where $\phi_{0}$ and $\phi_{v}$ are the solar and viewing azimuths (see Fig. 1). The CERES nextgeneration ADMs are described in Su et al. (2015), which improved upon the ADMs provided by Loeb et al. (2005). In this paper, we focus on details pertaining to the development and testing of the ADMs over clear Antarctic scenes that were briefly described in Su et al. (2015).

\subsection{Angular distribution models}

The CERES instrument consists of a three-channel broadband scanning radiometer (Wielicki et al., 1996). The scanning radiometer measures radiances in SW $(0.3-5 \mu \mathrm{m})$, win- 


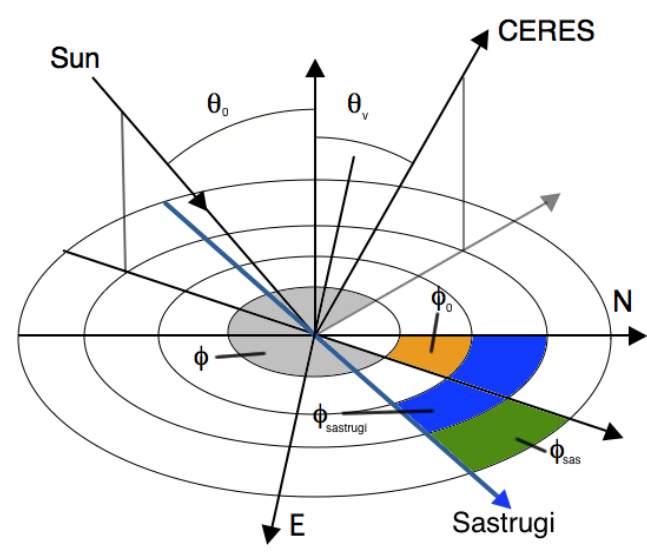

Figure 1. Diagram showing zenith and azimuth angles used in this study. $\theta_{0}$ and $\phi_{0}$ (orange section) indicate the solar zenith angle and azimuth angle (defined from north), respectively. $\theta_{v}$ is the viewing zenith angle of the CERES instrument. $\phi$ (grey section) is the relative azimuth angle between the CERES azimuth and the solar azimuth. The blue line indicates the direction of sastrugi, and the blue section shows sastrugi azimuth angle, $\phi_{\text {sastrugi }} . \phi_{\text {sas }}$ is the relative azimuth between the sastrugi azimuth and the solar azimuth and is illustrated by the green section.

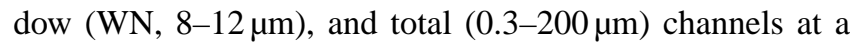
spatial resolution of $\sim 20 \mathrm{~km}$ at nadir. The LW component is derived as the difference between total and SW channels. These measured radiances at a given Sun-Earth-satellite geometry need to be converted to outgoing reflected solar and emitted thermal TOA radiative fluxes. To do so, we must account for the angular distribution of the radiance field, which is scene-type dependent. To facilitate the construction of ADMs, there are a pair of identical CERES instruments on both Terra and Aqua spacecraft. At the beginning of the mission, one of the instruments on each spacecraft was placed in a rotating azimuth plane (RAP) scan mode. In this mode, the instrument scans in elevation as it rotates in azimuth thus acquiring radiance measurements from a wide range of viewing geometries. To provide accurate information on scene types, CERES instruments are designed to fly alongside an imager (Moderate Resolution Imaging Spectroradiometer (MODIS) on Terra and Aqua). Cloud and aerosol retrievals from MODIS pixels (Minnis et al., 2011) are averaged over CERES footprints by accounting for the CERES point spread function (Smith, 1994) and are used for scenetype classification. For the clear-sky permanent snow scenes (mostly Greenland and Antarctica) examined in this paper, the existing ADMs were separated into two scene types, bright or dark (Kato and Loeb, 2005). The bright/dark classification was based upon the nadir $0.65 \mu \mathrm{m}$ reflectance from the MODIS imager for each $1^{\circ} \times 1^{\circ}$ grid box. Grid boxes whose mean radiance was less than the median grid box radiance for that month and solar zenith angle range were classified as dark, and those whose mean radiance was greater than or equal to the median radiance were classified as bright.
The general strategy of constructing ADMs is to sort the measured radiances into angular bins over different scene types. Over a given scene type $(j)$, a large ensemble of measured radiances are sorted into discrete angular bins. Averaged radiances in all angular bins $(\hat{I})$ are calculated and all radiances in the upwelling directions are integrated to provide the ADM flux $(\hat{F})$. The ADM anisotropic factors $(R)$ for scene type $j$ are calculated as

$$
\begin{aligned}
R_{j}\left(\theta_{0}, \theta_{v}, \phi\right) & =\frac{\pi \hat{I}_{j}\left(\theta_{0}, \theta_{v}, \phi\right)}{\int_{0}^{2 \pi} \int_{0}^{\frac{\pi}{2}} \hat{I}_{j}\left(\theta_{0}, \theta_{v}, \phi\right) \cos \theta_{v} \sin \theta_{v} d \theta_{v} d \phi} \\
& =\frac{\pi \hat{I}_{j}\left(\theta_{0}, \theta_{v}, \phi\right)}{\hat{F}_{j}\left(\theta_{0}\right)},
\end{aligned}
$$

where $\theta_{0}$ is the solar zenith angle, $\theta_{v}$ is the CERES viewing zenith angle, and $\phi$ is the relative azimuth angle between CERES and the solar plane. For an observed radiance $\left(I_{o}\right)$ under the same scene type, it is then converted to flux by using the anisotropic factor that we derived:

$F_{j}\left(\theta_{0}\right)=\frac{\pi I_{o}\left(\theta_{0}, \theta_{v}, \phi\right)}{R_{j}\left(\theta_{0}, \theta_{v}, \phi\right)}$.

\subsection{Sastrugi and BRDF of snow}

As the wind blows across the surface of Antarctica it forms, through the process of deposition and erosion, what are known as sastrugi (Gow, 1965). Sastrugi are dune-like features that align parallel to the wind direction. Their length and height are determined by the wind speed and can vary significantly, with reports of their size from $\langle 1 \mathrm{~m}$ to $\gg 10 \mathrm{~m}$ in length and from 0.04 to $>1 \mathrm{~m}$ in height (Gow, 1965; Frezzotti et al., 2002). They are larger at the end of winter and tend to decrease in size and flatten out over the summer (Gow, 1965). They are ubiquitous over much of Antarctica, and, due to the consistency of the katabatic winds, closely oriented in direction over large areas (Parish and Bromwich, 1987).

The fact that they are closely oriented over large areas means that, although their height can be small, they can have a significant effect on the BRDF (bidirectional reflectance distribution function) of snow seen by satellite-based instruments. This has been demonstrated using both MODIS (Kuchiki et al., 2011) and the Polarization and Directionality of Earth's Reflectances instrument (POLDER) (Mondet and Fily, 1999). Kuchiki et al. (2011) showed a diurnal cycle in the MODIS reflectances over the South Pole. As the satellite viewing geometry was fixed, the only change was the solar azimuth; thus, they attributed the cycle to sastrugi on the surface. Sastrugi alter the BRDF of snow by introducing a solar azimuth dependence. As the solar azimuth goes from parallel to the sastrugi axis to perpendicular, the reflectance in the forward-scattering direction is reduced and the reflectance in the backscattering direction is enhanced (Warren et al., 1998). They also cause the snow BRDF to lose its azimuthal 
symmetry. This was shown using POLDER data by Mondet and Fily (1999), who found variation in the BRDF of snow in East Antarctica. For areas of smooth snow with no sastrugi they show a forward-peaked BRDF and for areas with sastrugi they show a BRDF with a reduced forward-scatter peak and a larger backscatter peak. The BRDFs of the sastrugi areas also show that sastrugi introduce an azimuthal asymmetry as the position of the backscatter peak varied with geographic location. Sastrugi reduce the forward-scattered reflectance by shadowing and the backscattering is enhanced by the altering of the effective solar zenith angle (Warren et al., 1998). The magnitude of the decrease and increase depends on the solar zenith angle, the viewing zenith angle and the size of the sastrugi. With a more pronounced effect for larger sastrugi and at more oblique solar and viewing zenith angles. The density of the sastrugi field will also affect how much the BRDF changes, with a denser field having a larger effect (Zhuravleva and Kokhanovsky, 2011).

Several observational and modeling studies have found that sastrugi can cause a slight decrease in the albedo compared to flat snow (Warren et al., 1998; Carroll and Fitch, 1981; Zhuravleva and Kokhanovsky, 2011). This is due to the effective decrease in the solar zenith angle compared to the flat snow. For dense sastrugi fields, sastrugi-to-sastrugi reflections will also decrease the albedo by increasing the probability that a photon is absorbed, especially for longer wavelengths or broadband measurements (Warren et al., 1998). The magnitude of the change in albedo is generally found to be small, around 0.02 or less than a few percent (Carroll and Fitch, 1981; Leroux and Fily, 1998; Zhuravleva and Kokhanovsky, 2011; Warren et al., 1998).

The CERES TOA SW fluxes were found to be affected by sastrugi by Corbett et al. (2012). It was demonstrated that the albedo retrieved over areas close to the South Pole exhibited a sinusoidal shape as a function of solar azimuth angle. The variation was found to be around 0.08 from peak to trough or approximately $10 \%$ of the mean. This is much larger than the previous observational or modeling studies and was determined to be an artifact caused by the ADMs not accounting for changes in the BRDF caused by sastrugi. Sastrugi can create a bias because they change the shape of the BRDF, increasing the reflectance at some angles while decreasing it at other angles. If the ADMs fail to take this increase and decrease into account, then they can cause an over- or underestimate of the flux, depending on the viewing geometry. As snow is highly reflective, a small relative change in the BRDF due to sastrugi can create a large absolute change in the estimated flux. Over the rest of Antarctica, the sastrugi-induced bias was estimated by comparing the fluxes derived from nadir-only viewing zenith angles with those from all viewing angles. As sastrugi have a greater effect at more oblique angles, the nadir-only flux estimates are considered to be more accurate in the presence of sastrugi. Using this method, they were able to determine that sastrugi were causing statistically significant biases between -15 and
$15 \mathrm{Wm}^{-2}$, depending on the region and time of year. The contributions to the Antarctic-wide and global clear-sky TOA flux were -1 and $-0.01 \mathrm{Wm}^{-2}$, respectively; however, these were not statistically significant.

Sastrugi were identified as a potential problem as early as 1994 in relation to the ERBE (Earth Radiation Budget Satellite) instrument (Warren et al., 1998; Grenfell et al., 1994). Proposed solutions have included use of a sastrugi angle when creating ADMs (Grenfell et al., 1994) and simply using observations where the viewing angle is restricted in a way that the effects of sastrugi are avoided (Warren et al., 1998). The downfall with the first approach is that it requires accurate knowledge of the wind direction that caused the sastrugi, which is not necessarily the wind direction at the time of the radiance observation. As meteorological observations over much of Antarctica are sparse, the wind direction data may not be reliable. By introducing an additional angle one also reduces the sampling available for each $R$ value in Eq. (1), which may adversely affect the resulting ADMs. Using only the nadir views is a feasible solution and is the basis behind the method we use to determine the bias caused by sastrugi (Corbett et al., 2012). However, as this approach limits the regions sampled each day by CERES it could introduce spatial sampling biases into the long-term CERES record. The approach we have taken is to incorporate information from NASA's Multi-Angle Imaging Spectro-Radiometer (MISR) into our ADM creation process. We detail the method we use and the results in the sections below. As clouds effectively mask the surface the problem of sastrugi affecting the radiance-to-flux inversion is confined to clear-sky scenes only. This paper deals with clear-sky scenes over Antarctica only. The approach we use for ADMs over cloudy scenes and Greenland is detailed in Su et al. (2015).

\section{Data sets}

This study is conducted with the CERES Edition 4 Single Scanner Footprint (SSF) and the CERES Single Scanner Footprint-MISR (SSFM) data sets. The SSF data set consists of CERES radiances, fluxes, viewing geometry and geo-location information combined with MODIS radiances and cloud information derived from those radiances (Minnis et al., 2011), matched to the CERES field of view (FOV) and convoluted using the CERES PSF (Point Spread Function). The SSFM data set consists of the same SSF with the addition of co-located, and PSF-weighted, MISR radiance measurements. The MISR instrument (Diner et al., 1998) is also flying on NASA's Terra satellite. It consists of pushbroom-style cameras and provides near-simultaneous measured radiances of the same footprint from nine different viewing zenith angles (Df $/ \mathrm{a}= \pm 70.5^{\circ}, \mathrm{Cf} / \mathrm{a}= \pm 60.0^{\circ}, \mathrm{Bf} / \mathrm{a}$ $= \pm 45.6^{\circ}, \mathrm{Af} / \mathrm{a}= \pm 26.1^{\circ}$, and $\left.\mathrm{An}=0.0^{\circ}\right)$ in the along-track direction. MISR measures at four different wavelengths (blue $-446 \mathrm{~nm}$, green $-558 \mathrm{~nm}$, red $-672 \mathrm{~nm}$, and near-infrared 
$-867 \mathrm{~nm}$ ), with resolution ranging from $275 \mathrm{~m}$ at nadir to $1.1 \mathrm{~km}$ for the off-nadir cameras. The SSFM data set is discussed in more detail in Loeb et al. (2006). Additionally, we use the Modern-Era Retrospective Analysis For Research and Applications (MERRA) re-analysis data set to determine wind speed and direction (Rienecker et al., 2011).

\section{Method}

As noted above, sastrugi can strongly affect the BRDF of snow, with the effect depending on their orientation relative to the sun. When they are aligned parallel to the sun the reflectance in the forward-scattering direction is relatively higher, and the backscattering reflectance relatively lower than when the sastrugi are aligned perpendicular to the sun. This can be demonstrated using MISR measurements and the MERRA wind directions. If we assume that the sastrugi are aligned parallel to the mean wind field from MERRA, then we can sort the MISR measurements by the relative sastrugi angle, $\phi_{\text {sas }}=\phi_{\text {wind }}-\phi_{0}$. This is shown in Fig. 2. Here we have used the MISR near-infrared (NIR, $0.86 \mu \mathrm{m}$ ) reflectance $\left(\rho_{\text {nir }}\right)$ :

$\rho_{\text {nir }}=\frac{\pi I_{\text {nir }}}{F_{0, \text { nir }} \cos \left(\theta_{0}\right)} E_{0}^{2}$,

where $I_{\text {nir }}$ is the measured radiances, $F_{0 \text {,nir }}$ is the incoming solar flux in the MISR NIR band, $\theta_{0}$ is the solar zenith angle and $E_{0}$ is the Earth-Sun distance. We calculate the mean reflectance for each MISR camera, separating the scenes into three $\phi_{\text {sas }}$ bins: $0^{\circ} \leq \phi_{\text {sas }}<30^{\circ}$ (sastrugi mostly parallel to the sun, green line), $30^{\circ} \leq \phi_{\mathrm{sas}}<60^{\circ}$ (sastrugi neither parallel nor perpendicular to the sun, blue), and $60^{\circ} \leq \phi_{\text {sas }} \leq 90^{\circ}$ (sastrugi mostly perpendicular to the sun, red). The Figure shows that in the forward direction (positive viewing zenith angles) the reflectance is highest when the sastrugi are aligned parallel to the sun and decreases as the sastrugi become more perpendicular to the sun. The opposite occurs in the backscatter direction. The highest reflectance occurs when the sastrugi are aligned perpendicularly, decreasing as the sastrugi become parallel. This is what we would expect to happen and demonstrates that MISR is picking up a sastrugi signal in its measurements.

One of the underlying assumptions about ADMs is that the anisotropy does not change as the radiance changes. It is assumed that the radiances are positively correlated at all viewing geometries. This allows us to then assume that if a measurement at one viewing angle is greater than the mean, then the radiances at all the angles that we cannot simultaneously see are also greater than the mean. The anisotropy is then the same and the albedo scales accordingly. For singleviewing geometry instruments such as CERES there is no easy way to test this assumption. By using a multi-angle instrument such as MISR, which essentially gives us a slice of the instantaneous BRDF, we can test this. The results in

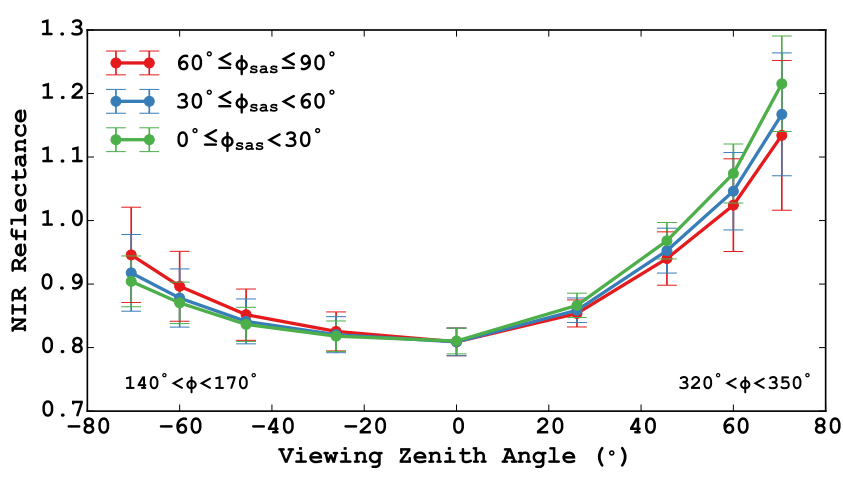

Figure 2. Mean MISR near-infrared reflectance over clear-sky Antarctica for $\theta_{0}=65-70^{\circ}$. The reflectances are separated by the $\phi_{\text {sas }}$ angle (see Fig. 1): $0^{\circ} \leq \phi_{\text {sas }}<30^{\circ}$ (green), $30^{\circ} \leq \phi_{\text {sas }}<60^{\circ}$ (blue), and $60^{\circ} \leq \phi_{\text {sas }} \leq 90^{\circ}$ (red). The error bars represent one standard deviation.

Fig. 2 suggest that this assumption is being violated and the presence of sastrugi causes the reflectance to become anticorrelated. This behavior is caused by the highly consistent orientation of the sastrugi and is not present for other scene types that do not have surface features with such a preferred azimuth (such as trees and clouds). As outlined briefly in $\mathrm{Su}$ et al. (2015), we examine this further using the joint probability distributions of standard scores between NIR reflectance $\left(\rho_{\text {nir }}\right)$ measurements from any two MISR cameras. The standard score is calculated as

$z_{\text {nir }}\left(\theta_{0}, \theta_{m}, \phi\right)=\frac{\rho_{\text {nir }}\left(\theta_{0}, \theta_{m}, \phi\right)-\bar{\rho}_{\text {nir }}\left(\theta_{0}, \theta_{m}, \phi\right)}{\sigma_{\rho_{\text {nir }}}\left(\theta_{0}, \theta_{m}, \phi\right)}$,

where the averages $\left(\bar{\rho}_{\text {nir }}\right)$ and standard deviation $\left(\sigma_{\rho_{\text {nir }}}\right)$ are calculated in $5^{\circ}$ bins for all available $\theta_{0}$ and $\phi$ at each MISR viewing angle, $\theta_{m}$. The absolute value of $z$ represents the departure of a measurement from the mean in units of the standard deviation, where negative $z$ indicates the measurement is below the mean and positive $z$ is above the mean. We use the NIR band of the MISR instrument as these radiances have the highest correlation with the CERES SW radiances for different solar zenith angles. We examine this by matching MISR and CERES radiances over clear-sky Antarctic scenes to within an angular separation of $5^{\circ}$, separating these matched radiances into $10^{\circ}$ solar zenith bins and calculating the correlation. For all solar zenith angles, the NIR has the highest correlation, ranging from $r^{2}=0.95$ for $50^{\circ} \leq \theta_{0}<60^{\circ}$ to $r^{2}=0.98$ for $80^{\circ} \leq \theta_{0}<90^{\circ}$. The MISR red band has the second-highest correlations, ranging from $r^{2}=0.92$ for $50^{\circ} \leq \theta_{0}<60^{\circ}$ to $r^{2}=0.98$ for $80^{\circ} \leq \theta_{0}<90^{\circ}$. The blue band has the worst correlations: from $r^{2}=0.69$ for $50^{\circ} \leq \theta_{0}<60^{\circ}$ to $r^{2}=0.95$ for $80^{\circ} \leq \theta_{0}<90^{\circ}$. The green band correlations lie between the blue and red bands. Based on these results we chose the NIR band to create the adjustments as it is most similar to the broadband.

Figure 3 shows the joint distributions of $z_{\text {nir }}$ between the forward viewing $\operatorname{Df}\left(\theta_{m}=70.5^{\circ}\right)$ camera and the remaining 

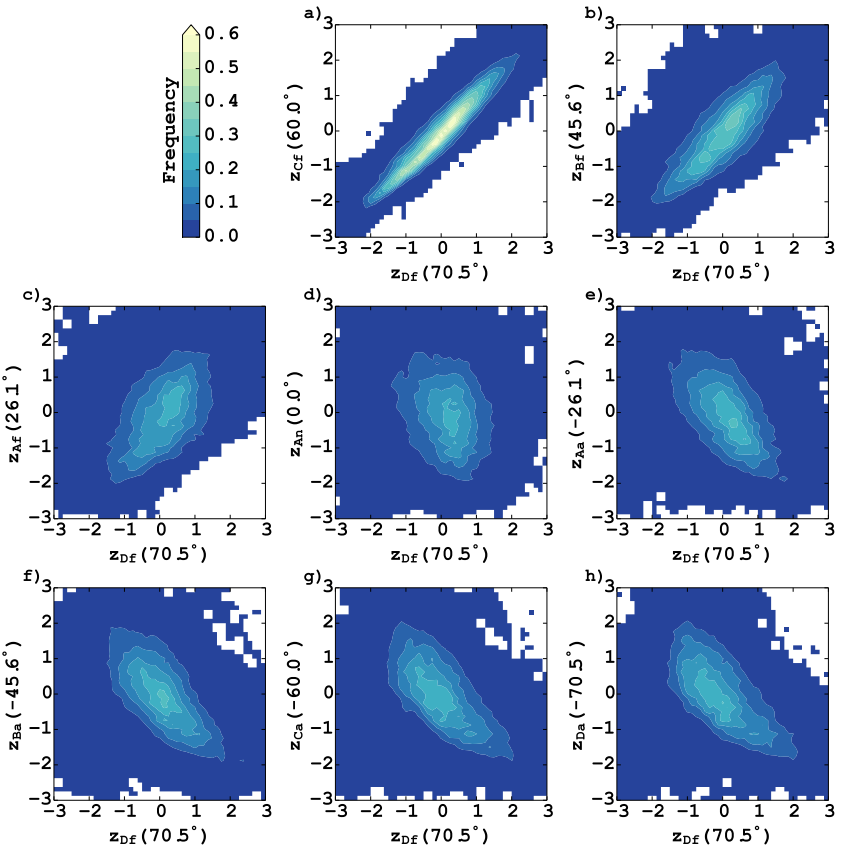

Figure 3. (a-h) Joint probability distributions $\left(P\left(z_{i}, z_{j}\right)\right)$ of NIR standard scores (see Eq. 4) between MISR's Df $\left(\theta_{m}=70.5^{\circ}, x\right.$ axis) and the remaining eight cameras. All $\theta_{0}$ and $\phi$ angles are included.

cameras. Distinct correlations can be seen in the figures, with the slope of the relationship changing as the angular distance between the cameras changes. There is a strong positive correlation at the adjacent camera, the correlation remains positive but decreases in strength as the viewing angle becomes less oblique. Once the viewing angle becomes negative, the correlation also becomes negative, increasing as the angles become more oblique. This indicates that the sastrugi are increasing the reflectance in one direction, while at the same time decreasing the reflectance in the opposite direction. We use these relationships to help us develop ADMs for CERES that take account of this observed behavior.

For other surfaces that might have a similar azimuthal alignment to that of sastrugi, namely desert sand dunes and ocean waves, the standard scores showed positive correlations between all the cameras. This indicates that these surfaces are not exhibiting sastrugi-like behavior. For sand dunes this may be due to the MISR relative azimuth sampling angles. As an example, for one desert area with large sand dunes known as the "Empty Quarter" $\left(44-56^{\circ} \mathrm{E}, 16-23^{\circ} \mathrm{N}\right)$ the forward-scatter-viewing mean-relative-azimuth ranges from $45^{\circ}$ (for $40^{\circ}<\theta_{0}<45^{\circ}$ ) to $68^{\circ}$ (for $10^{\circ}<\theta_{0}<15^{\circ}$ ). As these are closer to $90^{\circ}$ than to the principal plane, this limits our ability to detect any effect the sand dunes might have. A study by Wu et al. (2009) found that the presence of sand dunes in the Taklamakan Desert in China altered the MISR red band reflectance shape compared to a nearby dune-free area. However, when we applied the above approach to this same area $\left(77-88^{\circ} \mathrm{E}, 36-41^{\circ} \mathrm{N}\right)$ we found positive correla- tions between the standard score for all cameras. The reason for this discrepancy is not clear, it may be the result of the SSFM data set having reduced spatial and temporal sampling over desert areas compared to Antarctica, or it may be that this approach is not suitable for deserts which are less reflective than snow. For ocean scenes, the BRDF is largely dependent on the wind speed, which has been shown to affect the size and intensity of the glint region (Cox and Munk, 1954; Su et al., 2002). As the glint region is the dominant feature of the ocean BRDF, any changes in this due to wave orientation would likely be second-order to changes due to the wind speed, whereas it appears that the sastrugi-alignment is a first-order effect for sastrugi on snow.

\subsection{Development of adjustment factors}

The joint distributions show the statistical relationship between the reflectances from two cameras. They allow us to determine how changes in reflectance at one angle are related to changes at other angles. To create ADMs that utilize this we first calculate the standard scores for each of the MISR cameras using Eq. (4). For each camera pair, $i, j \in \theta_{m}$, we combine these to get the joint probability density functions (PDFs), $P\left(z_{i}, z_{j}\right)$. These are shown in Fig. 3 for the Df camera, i.e., $i=70.5^{\circ}, j \in\left\{\theta_{m}\right\}$. For each $j$ we use these joint PDFs to get the conditional probabilities of $i$ for seven discrete intervals of $z, P\left(z_{i} \mid z_{\gamma}<z_{j} \leq z_{\delta}\right)$, where $\left(z_{\gamma}, z_{\delta}\right) \in$ $(-3,-2),(-2,-1),(-1,-0.5),(-0.5,0.5),(0.5,1),(1,2)$, $(2,3)$. We then find the most likely value from these conditional probabilities, $E\left[P\left(z_{i} \mid z_{\gamma}<z_{j} \leq z_{\delta}\right)\right]$. As most of the conditional probabilities are normally distributed the most likely value is taken to be the mean. The conditional probabilities and corresponding mean values are shown in Fig. 4 for the case when $P\left(z_{i} \mid-1<Z_{D f} \leq-2\right)$. The progression from positive means to negative means with viewing angle changes can clearly be seen. The mean values provide the expected $z_{i}$ value when the $z_{j}$ value is within a certain range. In other words, the $z$ value of a reflectance measured with camera $j$ can be used to estimate what the $z$ value, and hence reflectance, will be at camera $i$. Relating this to CERES, we can think of this as $j$ being the angle CERES measures a radiance at and $i$ being the angle that CERES "cannot" see. The most likely value of the conditional probability for each of the nine MISR cameras and for each $z$ range is termed the adjustment factor and is denoted as $S\left(z_{i}, z_{j}\right)$, where $i=1,9$, and $j=1,9$.

To use these adjustment factors with CERES measurements, we first interpolate them to the same $\theta_{v}$ bin grid used in the CERES ADMs. For permanent snow this is a $5^{\circ}$ grid, i.e $\theta \in 0,5, \ldots, 90$. For correspondence with the MISR $\theta_{m}$ which are defined as negative when $\phi>90$, we use the set $\theta_{c}=-90,-85, \ldots, 85,90$. The interpolation is performed using a third-order spline interpolation scheme in the SciPy package (http://www.scipy.org). The interpolation requires two steps, the first interpolates along the $i$ axis, interpolat- 
ing $S\left(z_{i}, z_{j}\right)$ values from $\theta_{m}$ onto $\theta_{c}$, and the second step interpolates along the $j$ axis. We then split the values into the forward and backward directions of $\phi$, resulting in the array $S^{\prime}\left(z_{\theta_{i}, \phi_{i}}^{\prime}, z_{\theta_{j}, \phi_{j}}^{\prime}\right)$. This array can be interpreted in the same manner as $S$, but for CERES measurements. In this case $i=1,18$ and $j=1,18$, representing the CERES $\theta_{v}$ angles. If CERES measures a reflectance, with standard score $z^{\prime}$ at $\left(\theta_{i}, \phi_{i}\right)$, then $S^{\prime}$ tells us what the likely standard scores are at $\theta_{j}$ and $\phi_{j}$, the angles CERES cannot see. Note that as MISR does not have full azimuthal coverage the $S^{\prime}$ values are the same for all $0^{\circ} \leq \phi<90^{\circ}$ and for all $90^{\circ} \leq \phi<180^{\circ}$. We also do not include any solar zenith angle dependence in the adjustment factors. The standard scores themselves are calculated in solar zenith angle bins; however, we found that the joint PDFs were largely insensitive to the solar zenith angle, so the decision was made to not include the solar zenith angle dependence in the adjustment factors. This can be seen in Fig. 5 where solar-zenith-angle-dependent joint PDFs are shown for the Cf/Df cameras (a) and Da/Df cameras (b). The solid lines show the 50th percentile contour for each of the solar zenith angle ranges and the dashed lines show the 95th percentile. As can be seen, the joint PDFs show very little variation with solar zenith angle range for the adjacent forward cameras (Cf/Df). Between the Da/Df cameras there is slightly more variation with solar zenith range, especially for $50^{\circ} \leq \theta_{0}<60^{\circ}$; however, we do not believe it is different enough to need separate adjustment factors. For a given $\theta_{v}$ and $\phi$ angle, the adjustment factors are denoted as $\beta\left(\theta, \phi_{f / b}, z\right)_{\theta_{v}, \phi}$. Where $z$ corresponds to the standard score range of the measured radiance, and $\theta$ and $\phi_{f / b}$ indicate the viewing zenith angle and forward or backward relative azimuth directions.

The resulting adjustment factors for the CERES viewing zenith angle range, $65^{\circ}<\theta \leq 70^{\circ}$ in the forward direction, are shown in Fig. 6. By following a line it is possible to see how the adjustment factors change with viewing zenith angle and $z$ range. For example, when the $z$ value is between 1 and 2 (red squares), the adjustment values decrease from around 1.5 to 0 as the viewing angle decreases towards $\theta=0^{\circ}$. As the viewing angle goes negative (backward viewing direction) the adjustment factor continues to decrease before reaching a value of about -0.8 at $\theta=-70^{\circ}$. When the $z$ value is between -0.5 and 0.5 (green circles) the adjustment factors remain close to 0 for all angles. The adjustment factors corresponding to those from Fig. 4 are represented by the blue squares in Fig. 6. The actual values from the MISR measurements are shown by the orange stars, demonstrating how the values are interpolated from the MISR angles to the CERES angles.

\subsection{Construction of ADMs}

To construct the ADMs, we create a set of adjusted reflectance values $\rho_{\text {adj }}$, where the size of the adjustment de-

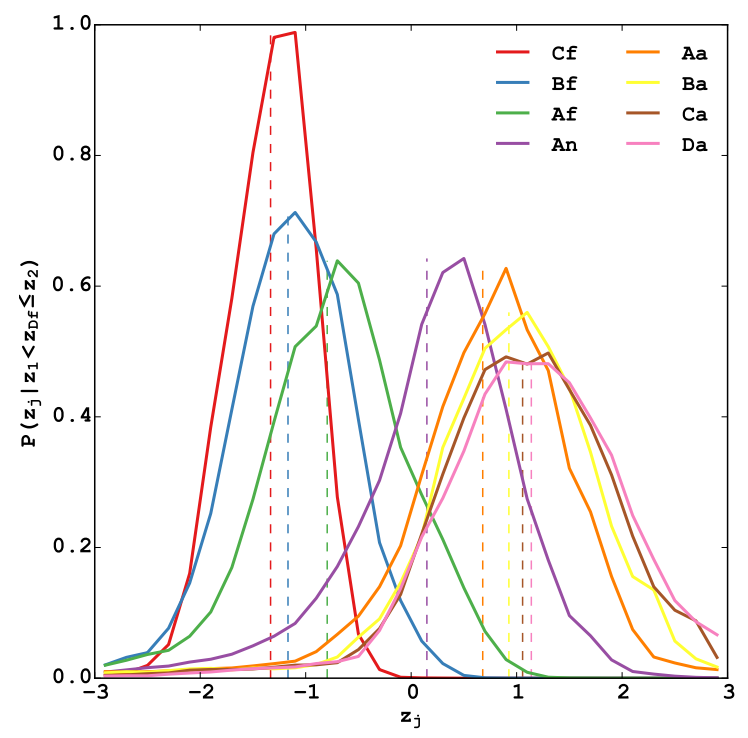

Figure 4. Conditional probability distributions $\left(P\left(z_{j} \mid-1<z_{D f} \leq\right.\right.$ $-2)$ ) of MISR cameras Cf-Da, for when the $z$ value of the Df camera is between -1 and -2 . The dashed vertical lines show the mean value.
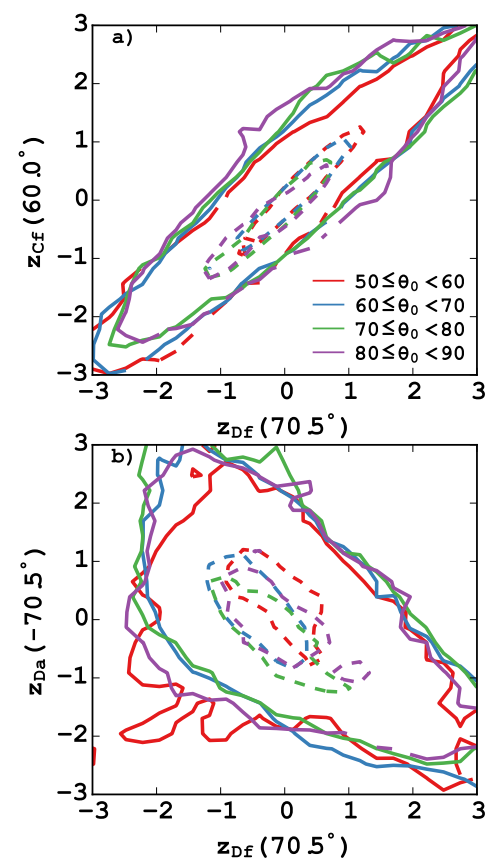

Figure 5. 50th (solid line) and 95th (dashed line) percentile contours of the joint probability distributions $\left(P\left(z_{i}, z_{j}\right)\right)$ of NIR standard scores (see Eq. 4) between MISR's Df and Cf cameras (a) and between MISR's Df and Da cameras (b). These joint PDFs were calculated for four solar zenith angle ranges.

pends upon the measurement viewing geometry and the standard-score range.

We first calculate the mean and standard deviation of the CERES clear-sky reflectances over Antarctica, using mea- 


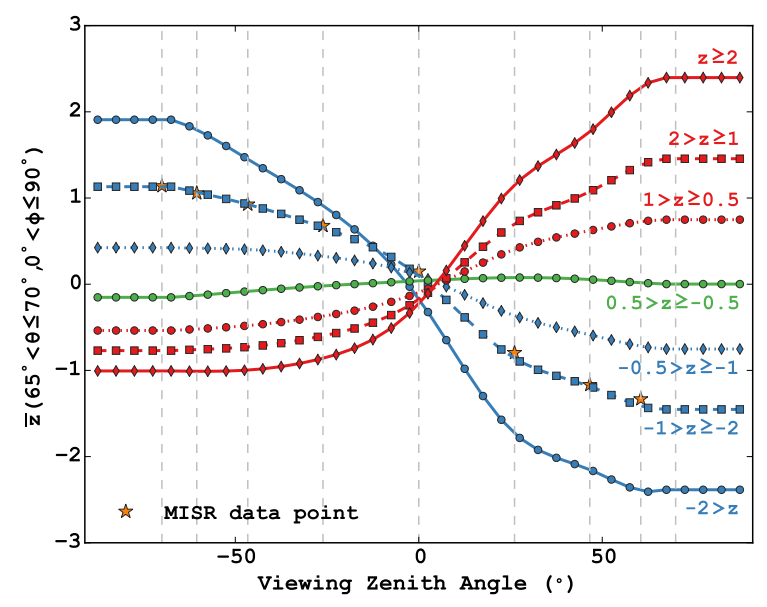

Figure 6. Adjustment factors interpolated from MISR angles (grey dashed lines) onto a $5^{\circ} \theta$ grid for use with CERES measurements. These adjustment factors are for the case when $65^{\circ} \leq \theta_{v}<70^{\circ}$ and $\phi<90^{\circ}$. Each of these lines represents a set from $\beta\left(\theta_{c}, \phi_{f / b}, z\right)_{\theta_{v}, \phi}$. The orange stars show the locations of the MISR values from which the blue squares' values were interpolated.

surements from both the Terra and Aqua satellites. This gives us $\bar{\rho}\left(\theta_{0}, \theta_{v}, \phi\right)$ and $\sigma\left(\theta_{0}, \theta_{v}, \phi\right)$, where $\theta_{0} \in\{0,2, \ldots, 86\}$, $\theta_{v} \in\{0,5, \ldots, 85\}$ and $\phi \in\{0,5, \ldots, 180\}$. Then, for each $\theta_{v}$, $\phi$, and $z$ in each $\left(z_{\gamma}, z_{\delta}\right)$ bin we select the relevant values from $\beta\left(\theta_{c}, \phi_{f / b}, z\right)_{\theta_{v}, \phi}$.

The $\rho_{\text {adj }}$ values are then calculated as

$$
\begin{aligned}
& \rho_{\text {adj }}\left(\theta_{0}, \theta_{v}, \phi, \theta_{c}, \phi_{f / b}, z\right)=\bar{\rho}\left(\theta_{0}, \theta_{v}, \phi\right)+\sigma\left(\theta_{0}, \theta_{v}, \phi\right) \\
& \quad \times \beta\left(\theta_{c}, \phi_{f / b}, z\right)_{\theta_{v}, \phi} .
\end{aligned}
$$

Any viewing geometry bins without measurements (very oblique angles or solar avoidance angles) are filled in using the BRDFs of Hudson et al. (2010). The adjusted reflectances are then integrated over all upwelling directions, for each combination of $\theta_{c}, \phi_{f / b}$, and $z$, and the ADMs are derived from Eq. (1), giving us $R\left(\theta_{0}, \theta, \phi\right)_{\theta_{c}, \phi_{f / b}, z}$.

\subsection{Application of the ADMs}

To apply the ADMs to a CERES reflectance measurement, we first calculate the $z$ value of the measured reflectance using previously calculated mean and standard deviation values as in Eq. (4). We then select the appropriate $\theta_{i}, \phi_{i}$ and $\left(z_{\gamma}, z_{\delta}\right)$ values, which give us the correct ADM to use. The ADMs are then applied as in Eq. (2). In order to not introduce any discontinuities we also interpolate the $R$ values between $z$ range bins.

\section{Results}

Figure 7a shows the mean CERES clear-sky reflectance (red line) for the region $88-89^{\circ} \mathrm{S}, 76-83^{\circ} \mathrm{W}$, averaged over all

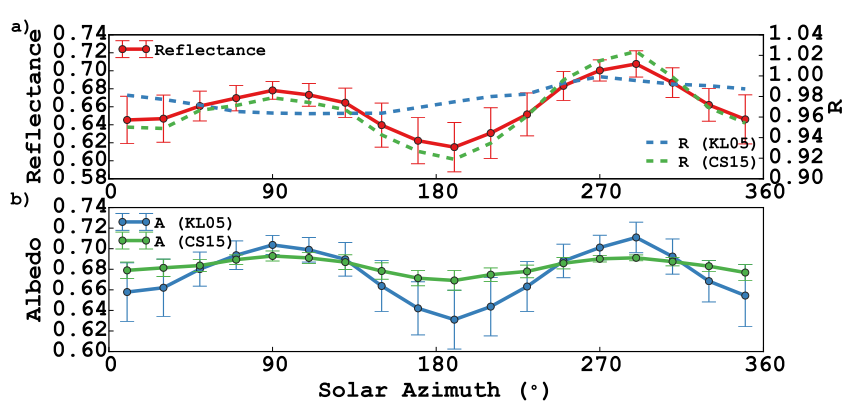

Figure 7. (a) Mean CERES reflectance (red line, left scale) in $20^{\circ}$ $\phi_{0}$ bins for the region $88-89^{\circ} \mathrm{S}, 76-83^{\circ} \mathrm{W}$ over all Decembers from 2000 to 2004 . The viewing geometry range of the measurements is (for relative azimuth, viewing zenith, and solar zenith, respectively), $65^{\circ} \phi<75^{\circ}, 45^{\circ}<\theta<65^{\circ}$, and $65^{\circ}<\theta_{0}<70^{\circ}$. The dashed blue line shows the mean anisotropic factor (right scale) used to invert these reflectances into fluxes from the KL05 ADMs. The dashed green line shows the same but for the ADMs developed here (CS15). (b) Mean CERES albedo for the same region and viewing geometry in (a) for the KL05 ADMs (blue) and CS15 ADMs (green line). Error bars represent 1 standard deviation.

Decembers from 2000 to 2004 as a function of the solar azimuth angle. At this latitude, sampling is available at all solar azimuth angles and a limited viewing zenith angle $\left(45^{\circ}<\theta<65^{\circ}\right)$ range at a fixed relative azimuth angle $\left(65^{\circ}<\phi<75^{\circ}\right)$. The reflectance shows a clear sinusoidal signal as a function of the solar azimuth angle. This suggests that there is a surface feature that periodically brightens and then darkens the reflectance with azimuth, i.e sastrugi. The mean anisotropic values used to convert the reflectance to albedo are also shown in dashed lines. The anisotropic factors from Kato and Loeb (2005) (hereafter KL05) (Fig. 7a dashed blue) are fairly constant across the solar azimuth range, whereas the new anisotropic factors (Fig. 7a, dashed green) follow the shape of the reflectance curve more closely. The corresponding mean albedos are shown in Fig. 7b with albedos inverted using KL05 ADMs in blue and using the ADMs described in this paper (hereafter CS15) in green. The KL05 albedo also follows a sinusoidal shape with solar azimuth. Although sastrugi are expected to alter the albedo slightly with solar azimuth angle, the change is much larger than expected. Also, as the relative azimuth is about $70^{\circ}$, the change in albedo is not in the correct phase with respect to the solar azimuth (the maximum albedo would occur when the sun is aligned perpendicular to the sastrugi, which is an offset of about $70^{\circ}$ ). This is a result of the anisotropic factors being relatively constant across the solar azimuth range. The CS15 albedos show a slight variation with solar azimuth; however, the dependence is greatly reduced. This indicates that the CS15 albedo retrievals behave more realistically with the solar azimuth than the KL05 ADMs, and that the anisotropic factors are more accurately compensating for the change in 

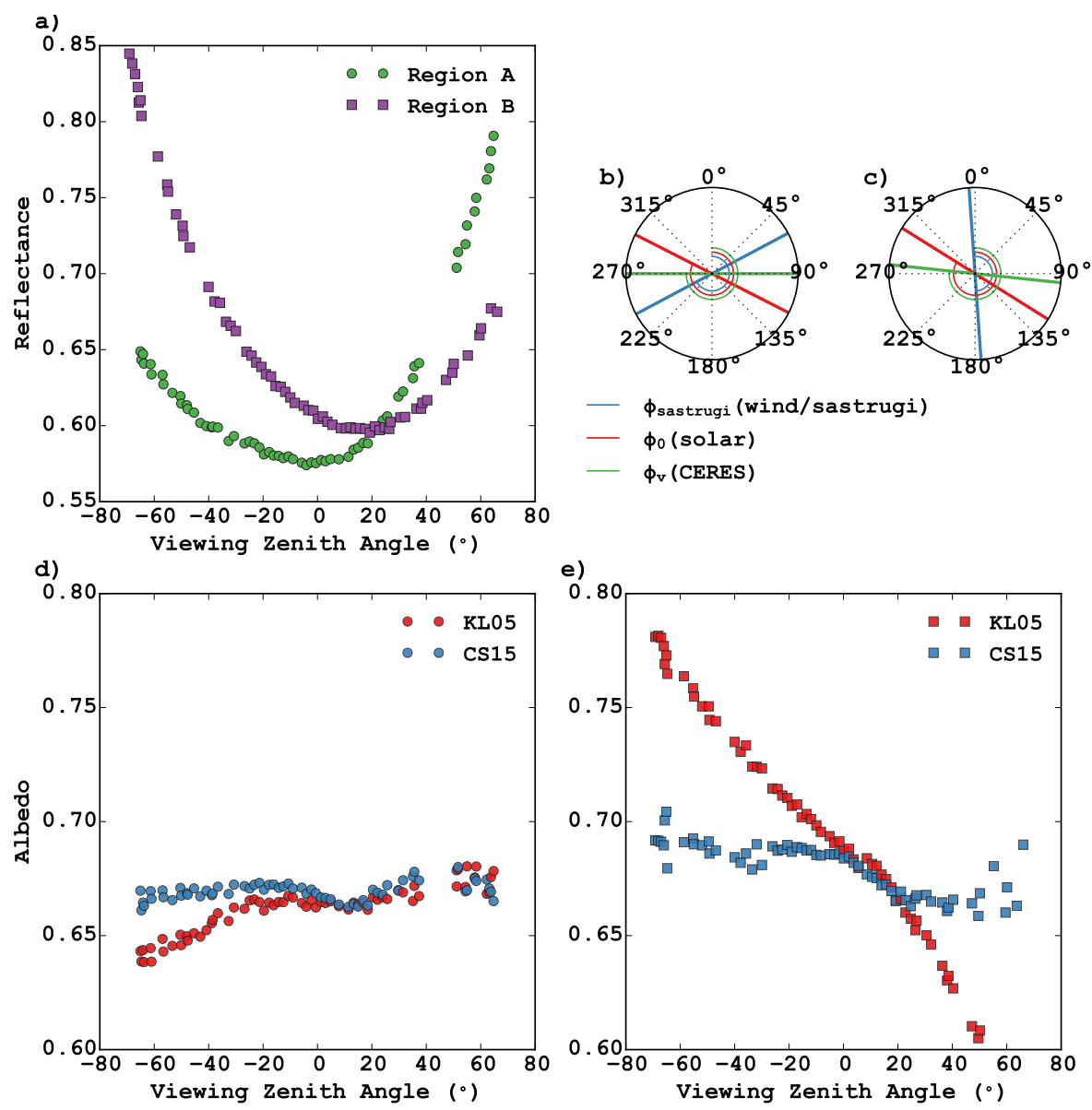

Figure 8. (a) Instantaneous clear-sky CERES reflectance values against viewing angle for two $1^{\circ} \times 1^{\circ}$ grid boxes: $81^{\circ} \mathrm{S}, 163^{\circ} \mathrm{W}(\mathrm{green}$ circles, 28/12/2004) and $81^{\circ} \mathrm{S}, 35^{\circ} \mathrm{E}$ (purple squares, 16/12/2003). (b) and (c) viewing and sastrugi azimuth (from the north) for the two grid boxes in (a) when the measurements were made; viewing azimuth (green line), $\phi_{\text {sastrugi }}$ (blue), and $\phi_{v}$ (red line). (d) Albedo against viewing zenith angle for the grid box $81^{\circ} \mathrm{S}, 163^{\circ} \mathrm{W}$ calculated using KL05 ADMs (red) and CS15 ADMs (blue). (e) as in (c) but for the grid box $81^{\circ} \mathrm{S}, 35^{\circ} \mathrm{E}$.

reflectance. The standard deviation is greatly reduced too, suggesting the retrievals are more consistent.

Figure $8 \mathrm{a}$ shows the reflectance values against viewing zenith angle for two separate $1^{\circ} \times 1^{\circ}$ grid boxes over Antarctica; circles $\left(81^{\circ} \mathrm{S}, 163^{\circ} \mathrm{W}, \mathrm{A}\right)$, squares $\left(81^{\circ} \mathrm{S}, 35^{\circ} \mathrm{E}, \mathrm{B}\right)$. These measurements were acquired when one of the CERES instruments was scanning in along-track mode, so it sees the same area from different viewing zenith angles but with a fairly constant relative azimuth angle close to the principal plane $\left(\phi \approx 20^{\circ}\right)$. As can be seen, the reflectance curves from the two regions have quite different shapes. Grid box B (purple squares) has a much higher backward peak than grid box A (green circles) which has a higher forward peak. The difference in shape can be understood by looking at the viewing geometry angles shown in Fig. $8 \mathrm{~b}$ and c. The green line shows the viewing azimuth with respect to north $\left(0^{\circ}\right)$, the red line shows the solar azimuth. The blue line shows our estimate of the sastrugi direction, based upon the mean wind direction from the MERRA data set over the period 2000-
2004. The viewing geometry is fairly similar in both cases, with the viewing azimuth close to $270^{\circ}$ and the solar azimuth around $300^{\circ}$. The main difference between the two is the wind direction or sastrugi angle. In the first region, the sastrugi angle is more parallel to the solar azimuth angle and the viewing azimuth is about $30^{\circ}$ off the sastrugi angle. In the second region, the sastrugi angle is approximately north-south, resulting in a viewing angle almost perpendicular to the sastrugi. This is consistent with the higher backward peak and lower forward peak seen in the reflectance. The corresponding albedo retrievals against viewing zenith angle for the two regions are shown in Fig. 8d and e. Ideally, the albedo at a given location should be independent of viewing zenith angle. However, we see that the KL05 ADMs (shown in green) return a very systematic dependence of albedo on viewing zenith angle. This is especially true for the region $\mathrm{B}$ where albedo varies from 0.78 to 0.60 as the viewing zenith goes from $-70^{\circ}$ (i.e., backward viewing) to $60^{\circ}$ (forward viewing). While the FOVs from the different 
angles are not all looking at exactly the same area, there is considerable overlap and it is hard to believe that the albedo is actually varying by this much over such a small area, indicating that the retrievals are probably erroneous. For region $\mathrm{A}$, the dependence is not as large, yet we do see an increase in the KL05 albedo from the backward viewing to the forward viewing angles. In both regions the albedos retrieved using the CS15 ADMs are much flatter with viewing zenith angle. This indicates that these ADMs are better at accounting for the variation of anisotropy caused by sastrugi.

To estimate the monthly grid box level bias over Antarctica due to sastrugi we first calculate the $24 \mathrm{~h}$ equivalent flux for each flux measurement using the method described in Loeb and Manalo-Smith (2005). Briefly, this method uses the instantaneous albedo and the diurnal variation of the KL05 ADM albedos to estimate what the reflected SW flux would be at any time over a $24 \mathrm{~h}$ period for a given location, assuming there are no changes in the atmospheric or surface properties. The average of these values is then the estimate of the $24 \mathrm{~h}$ mean reflected SW flux, $\hat{F}_{24 \mathrm{~h}}$. Equation 3 of Loeb and Manalo-Smith (2005) describes this mathematically as

$$
\hat{F}_{24 \mathrm{~h}}=\frac{\hat{A}\left[\theta_{0}\left(t_{0}\right)\right]}{\alpha_{k}\left[\theta_{0}\left(t_{0}\right)\right]}\left\{\frac{1}{N_{t}} \sum_{l=1}^{N_{t}} \alpha_{k}\left[\theta_{0}\left(t_{l}\right)\right] \mu_{0}\left(t_{l}\right) F_{0}\right\},
$$

where $\hat{A}$ is the estimated instantaneous albedo determined using Eq. (3), $t_{0}$ is the time of observation, $\alpha_{k}\left[\theta_{0}\left(t_{l}\right)\right]$ is the scene-type-dependent $(k)$ ADM albedo at the solar zenith angle corresponding to local time $t_{l}, l$ is the time step increment, $N_{t}$ is the number of time steps used to compute the $24 \mathrm{~h}$ flux and $\mu_{0}\left(t_{l}\right)$ is the cosine of the solar zenith angle at $t_{l} . F_{0}$ is, as above, the TOA solar insolation. To improve calculation speed the $\left(1 / N_{t}\right) \sum_{l=1}^{N_{t}} \alpha_{k}\left[\theta_{0}\left(t_{l}\right)\right] \mu_{0}\left(t_{l}\right) F_{0}$ term is pre-calculated for each Julian day at a resolution of $1^{\circ}$ in latitude and $1 \mathrm{~min}$ in time and stored in a look-up table.

We then calculate two estimates of the $\hat{F}_{24} \mathrm{~h}$ for each $1^{\circ} \times 1^{\circ}$ grid box. The first estimate, $\hat{F}_{24} \mathrm{~h}$, is calculated using measurements from all viewing zenith angles. The second, $\hat{F}_{24 \mathrm{~h}}^{n}$, from measurements where the viewing zenith angle is close to nadir $\left(\theta<20^{\circ}\right)$. We then define the bias as the difference between the flux calculated from all angles and the flux from nadir angles:

$$
\Delta \hat{F}_{24 \mathrm{~h}}=\hat{F}_{24 \mathrm{~h}}-\hat{F}_{24 \mathrm{~h}}^{n} \text {. }
$$

This is the procedure used in Corbett et al. (2012), and it allows us to estimate what effect sastrugi have on the mean TOA flux over Antarctica. The idea is that the sastrugi will have the most impact on the ADMs at more oblique angles than at the nadir angles; thus, the difference between the total flux and near-nadir flux will provide an estimate of the bias in the averaged monthly level 3 CERES data products. We performed this analysis for the austral summer months (October-March) for 4 years of Edition 4 SSF data from 2001 to 2004, for both the CS15 and KL05 ADMs. In this analysis we consider values in the upper and lower 0.5 percentiles to be outliers and exclude them, this allows us to make a more consistent comparison between the two ADMs. Figure 9a shows the 0.5-99.5 percentile range (whiskers) and 25th-75th percentile range (box, also referred to as the interquartile range) of the $\Delta \hat{F}_{24} \mathrm{~h}$ for each month listed. The dots show values of the outliers and the stars indicate that there are values outside the $\pm 15 \mathrm{Wm}^{-2}$ axis limits. The blue box/whiskers/dots are the CS15 ADM results and the red are the KL05 ADM results. The green line within the box shows the median value and the grey line the mean value (not area-weighted). The box/whisker values here show that the CS15 $\Delta \hat{F}_{24} \mathrm{~h}$ tend to have a narrower range than the KL05 $\Delta \hat{F}_{24} \mathrm{~h}$. The month with the largest KL05 $\Delta \hat{F}_{24 \mathrm{~h}}$ range is December 2002 (DEC 02), from -12 to $7.5 \mathrm{Wm}^{-2}$. The range of CS15 $\Delta \hat{F}_{24 \mathrm{~h}}$ for December 2002 is -5 to $4 \mathrm{Wm}^{-2}$, the mean and median have shifted closer to 0 , and the interquartile range has also decreased. The interquartile range has decreased for all months, indicating a significant decrease in the spread of the $\Delta \hat{F}_{24 \mathrm{~h}}$ when using the CS15 ADMs instead of the KL05 ADMs. The maximum positive bias for the CS15 ADMS is $7 \mathrm{Wm}^{-2}$ (December 2004), down slightly from $7.5 \mathrm{Wm}^{-2}$ for the KL05 ADMs (December 2003). The maximum negative CS15 bias is $-5 \mathrm{Wm}^{-2}$ (December 2004), down significantly from $-12 \mathrm{Wm}^{-2}$ for the KL05 ADMs (December 2002). An interesting aspect of this plot is the seasonal dependence of the $\Delta \hat{F}_{24 \mathrm{~h}}$ values. The biases tend to be higher in December and lower in October and March. Part of this is because Antarctica receives more sunlight in December, so the $24 \mathrm{~h}$ bias will be higher, but part of it is likely due to the sastrugi decreasing in size over the summer. Gow (1965) observed this decrease in sastrugi over the summer months at the south pole due to erosion an sublimation. If we compare months that have similar sunlight hours (i.e., October/March, November/February, and December/January, though there are some differences in incoming solar) we see that the months that occur earlier in the summer have higher biases than the late-summer months. This is especially true for the KL05 ADMs, the CS15 ADMs do show this but with a reduced magnitude, further indicating they are accounting for the sastrugi effects. Note that the tests we perform here are designed to capture biases caused by sastrugi, it is possible that other biases may exist in the CERES fluxes (e.g., scene identification errors) but these would require additional tests to be determined.

Figure $9 \mathrm{~b}-\mathrm{g}$ show the maps of $\Delta \hat{F}_{24 \mathrm{~h}}$ for November 2002 (b, c), December 2002 (d, e), and January 2003 (f, g) for both $\operatorname{KL} 05$ (b, d, f) and CS15 (c, e, g). The largest sastrugi bias effects can be seen in the KL05 ADMs over the east Antarctic Plateau area, especially on the eastward slope. The CS15 ADMs show that the bias has decreased over most of Antarctica. The distinct pattern of the bias over the east Antarctic Plateau can still be seen; however, its magnitude has been reduced, with both the large positive and negative biases smaller in the CS15 plots than in the KL05 plots. 

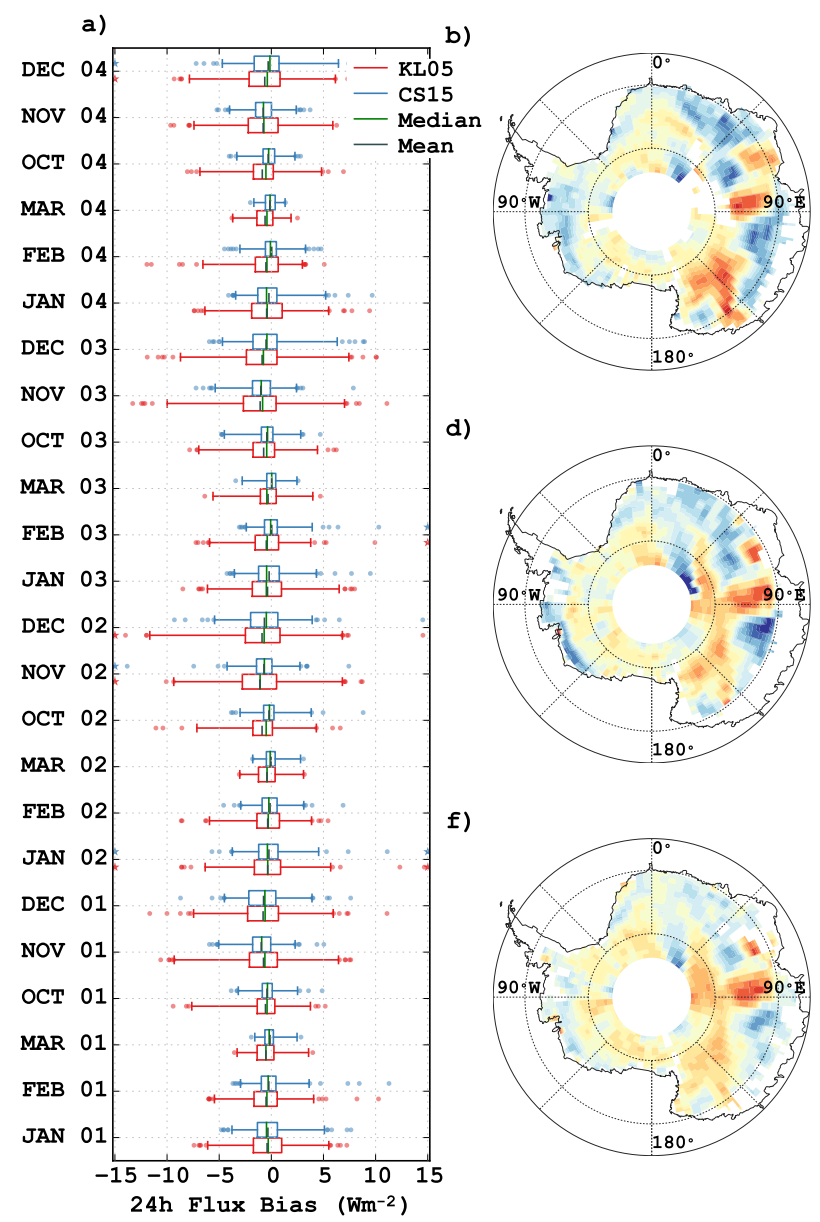

c)

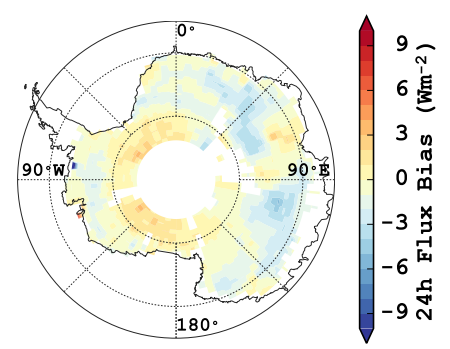

d)

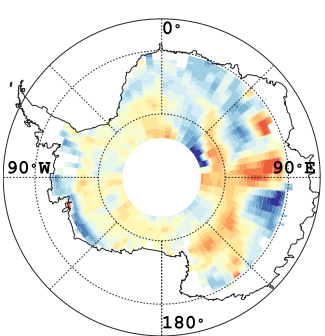

e)

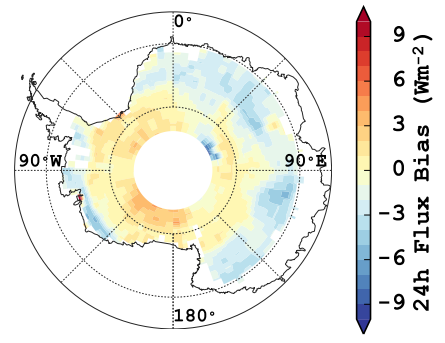

f)

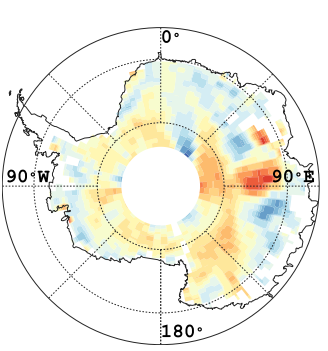

g)

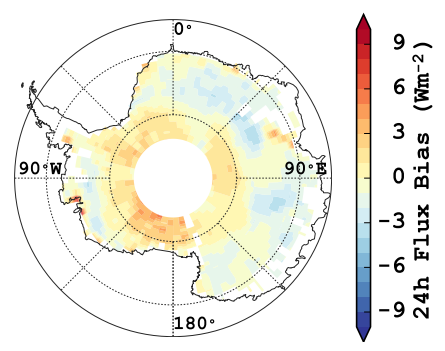

Figure 9. (a) Box and whisker comparison of grid-box mean $24 \mathrm{~h}$ flux biases $\left(\mathrm{Wm}^{-2}\right.$ ) (see Eq. 6) for the months October-March for 2001-2004. The whiskers show the 0.5-99.5 percentile range of the biases for each year, the boxes show the interquartile range (25th-75th percentile range), and the dots show the outliers. Stars indicate that there are values outside the axis range. Medians are shown by the green line and means by the grey line. The $24 \mathrm{~h}$ flux biases calculated using the KL05 ADMs are shown in red and those calculated using the CS15 ADMs (this study) are shown in blue. (b)-(g) show maps of the grid-box biases for November 2002 (b, c), December 2002 (d, e), and January 2003 (f, g). The middle column (b, d, f) shows maps of the bias calculated using the KL05 ADMs, and the right column (c, e, g) shows the bias maps when using the CS15 ADMs.

There are two regions where the bias seems to have actually increased when using the CS15 ADMs. One of these is approximately located between 135 and $180^{\circ} \mathrm{W}$ and north of $80^{\circ} \mathrm{S}$. The other region is approximately between 30 and $60^{\circ} \mathrm{W}$ and north of $80^{\circ} \mathrm{S}$. Interestingly, these correspond, respectively, to the Ross and Ronne ice shelves and the relatively steep slopes that lead to them. It suggests that they may have a slightly different anisotropy compared to the rest of Antarctica, and may need to be accounted for in future ADMs. These positive biases may explain why the range of $\Delta \hat{F}_{24 \mathrm{~h}}$ for CS15 decreased more on the negative side than on the positive side in Fig. 9a.

Generally, the area-weighted mean bias and area-weighted standard deviation of the $\Delta \hat{F}_{24} \mathrm{~h}$ values have both decreased for all of the months we looked at when using the CS15 ADMs. The largest absolute change in the mean bias oc- curred for October 2002 where the mean $\Delta \hat{F}_{24 \mathrm{~h}}$ decreased from -0.87 to $-0.23 \mathrm{Wm}^{-2}$ and the largest relative change was in February 2004 where the mean $\Delta \hat{F}_{24} \mathrm{~h}$ decreased from -0.53 to $0.03 \mathrm{Wm}^{-2}$, a relative decrease of $95 \%$ (using absolute values to calculate the difference). Only 1 month showed an increase in mean bias, November 2001, where the mean $\Delta \hat{F}_{24 \mathrm{~h}}$ increased from -0.77 to $-0.97 \mathrm{Wm}^{-2}$. Otherwise the changes in the mean $\Delta \hat{F}_{24 \mathrm{~h}}$ ranged from -0.02 to $-0.64 \mathrm{Wm}^{-2}$ or, using relative changes, from -2 to $-95 \%$. The standard deviation of the $\Delta \hat{F}_{24 \mathrm{~h}}$ decreased for all of the months we looked at, with relative decreases between $-24 \%$ (January 2004) and $-56 \%$ (November 2002). In absolute values these decreases were from 2.02 to $1.54 \mathrm{Wm}^{-2}$ and from 2.89 to $1.26 \mathrm{Wm}^{-2}$, respectively. As this is clear-sky only, and as Antarctica occupies a relatively small portion of the globe, these biases (and the reduction in bias from the 
a)

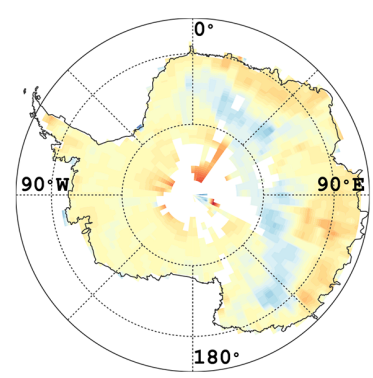

d)

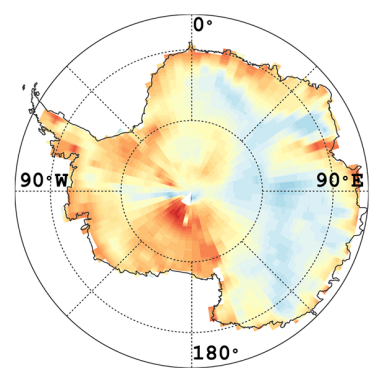

b)

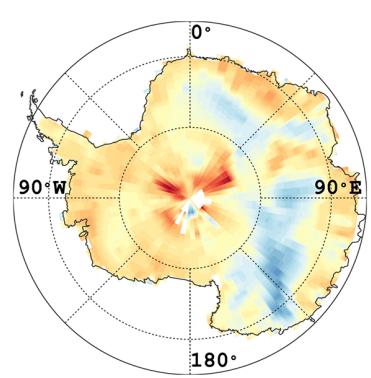

c)

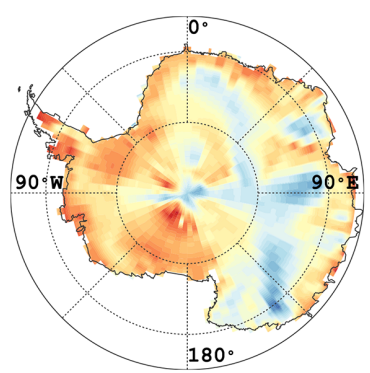

e)

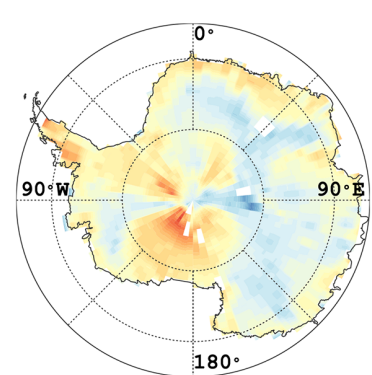

f)

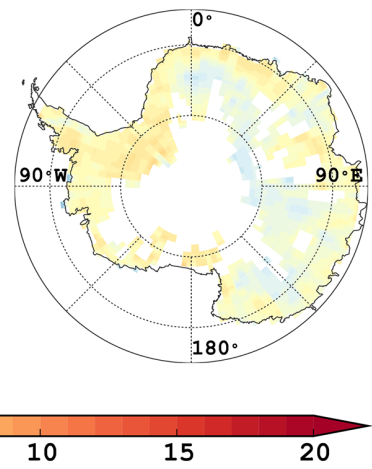

Figure 10. Difference in clear-sky $\bar{F}_{24}\left(\mathrm{Wm}^{-2}\right)$ between CS15 and KL05 ADMs for (a)-(f) October-March of 2002. Difference is calculated as $\Delta \bar{F}_{24}=\bar{F}_{24}^{C S 15}-\bar{F}_{24}^{K L 05}$.

CS15 ADMs) have a negligible effect on the global monthly reflected SW flux value.

The change in the mean $24 \mathrm{~h}$ flux between the KL05 and CS15 ADMs is shown in Fig. 10 for the months OctoberMarch for 2002. The changes are generally quite small at the grid box level, within $20 \mathrm{Wm}^{-2}$, and a maximum $2 \sigma$ range of $4.5 \%$ of the mean $24 \mathrm{~h}$ flux (equivalent to $7.4 \mathrm{Wm}^{-2}$ in October), or $12.2 \mathrm{Wm}^{-2}$ (3.6\% of the mean $24 \mathrm{~h}$ flux in December). The Antarctic-wide mean changes range from $-1.9 \mathrm{Wm}^{-2}$ in November to $1.4 \mathrm{Wm}^{-2}$ in January. Qualitatively, the changes in flux show a similar pattern to the KL05 bias maps, with the sign reversed. This is especially noticeable over eastern Antarctica, where the positive biases over the ridge of the plateau have become negative flux changes and the positive biases along the slopes at 90 and $135^{\circ} \mathrm{E}$ are associated with negative flux changes. The negative flux biases located approximately between 0 and $45^{\circ} \mathrm{E}$, north of $75^{\circ} \mathrm{S}$, are associated with positive flux changes, as are the negative flux biases between 90 and $135^{\circ} \mathrm{E}$. The flux changes also capture to some extent the alternating biases located between 45 and $90^{\circ} \mathrm{E}$. The changes are as we expect, negative biases, suggesting we were underestimating the flux, are associated with positive flux changes. Positive flux biases, indicating overestimation of the flux, are associated with negative flux changes. The correlation between flux changes and bias is shown in Fig. 11, with Fig. 11a showing the correlation for all of Antarctica and Fig. 11b showing the correlation for the eastern part of Antarctica between 0 and $180^{\circ} \mathrm{E}$. The correlation coefficients are -0.33 and -0.48 , respectively. The improved correlation for the eastern part seems to stem from excluding the large flux increases over the Ross and Ronne ice sheets in the western part of Antarctica in December and January. These large flux increases are not associated with a negative flux bias, suggesting that the new ADMs might be overestimating the fluxes in these areas. However, in general, the relationship between biases and flux changes is as we would expect it to be and provides further support for this new method of creating ADMs.

\section{Discussion}

Due to the along-track sampling of the MISR instrument, and Terra's polar orbit, the SSFM data used here are only available close to the principal plane. This means that the relationships we derive between the cameras are only really valid for that region. We assume here that the relationships hold as the relative azimuth changes. Unfortunately, there is no way to test this assumption as it is not possible to get simultaneous measurements of the same location from different viewing zeniths at the relative azimuths sampled by CERES at high latitudes, approximately $70-80^{\circ}$ and $100-110^{\circ}$ while in cross-track mode. However, the standard deviation used to 

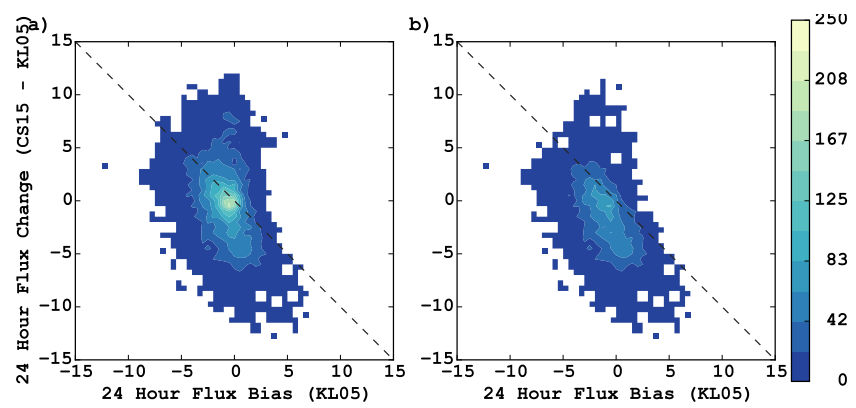

Figure 11. (a) Density plot between the grid box level $\Delta \bar{F}_{24}$ ( $y$ axis) and the $24 \mathrm{~h}$ flux bias (from KL05 ADMs) for the months October-March for the years 2000-2004 for all valid grid boxes over Antarctica. (b) as in (a) with the grid boxes only limited to the eastern portion $\left(0-180^{\circ} \mathrm{E}\right)$ of Antarctica.

calculate the ADMs is generally lower at these angles than at the principal plane angles. This means the change in albedo possible from these angles is much less than from the principal plane angles which have higher standard deviations. We note that some of the above results can be used as a form of validation of this assumption. Especially the results in Fig. 7, which test the ADMs from cross-track angles with a wide range of reflectance values. The consistent results achieved regardless of the reflectance values suggests that this assumption is valid.

Another limitation is that the absolute value of the CERES reflectance and the standard deviation is used to determine which ADM to use. By doing this we are assuming that the mean reflectance and standard deviation calculated for the period 2000-2005 will remain unchanged for the rest of the record (a length of time as of yet undetermined). This is not a completely unrealistic assumption, as the expected changes in Antarctic snow surface properties (mainly snow grain size) that would affect the absolute brightness are very minimal (Picard et al., 2012). As we also use an interpolation scheme between standard deviation bins, this limits the effect that any shifts in the distribution might have on the anisotropic factor and, hence, the final albedo.

A third source of potential error is the use of the MISR ellipsoid-projected radiances in the SSFM data set. The ellipsoid-projected radiances are projected onto the WGS (World Geodetic System) 84 surface ellipsoid. This means that over the high Antarctic Plateau the radiances, registered to the same point on the ellipsoid, will be offset slightly at the true surface. Based upon the height of the Antarctic Plateau $(\approx 3 \mathrm{~km})$ above the ellipsoid and the height of Terra's orbit (705 km), this offset will be $\approx 10 \mathrm{~km}$ between the Da and Df cameras. However, this offset is still within the size of the CERES FOV $(20 \mathrm{~km})$ at nadir, so at least within the CERES footprint the cameras will be viewing portions of the same scene. Because of the CERES footprint size and the largescale homogeneity of the Antarctic Plateau, this is unlikely to cause any significant errors; however, it probably contributes to the noise between the Df and Da cameras in Fig. 3.

\section{Conclusions}

Sastrugi are an interesting problem for radiance-to-flux inversion. They have the ability to significantly alter the BRDF, without changing the albedo. Capturing this in a consistent and physically plausible way is important to accurately estimate the albedo and irradiance over clear-sky Antarctica. In our attempt to find a solution to this issue we have incorporated the multi-angle information from MISR into the creation of the CERES clear-sky Antarctic snow ADMs. By using angular relationships derived from MISR we are able to create a set of ADMs that successfully removes most of the bias caused by the sastrugi. To examine the bias caused by sastrugi on the reflected SW flux, we compare measurements taken from nadir angles only, which are less sensitive to sastrugi, with those taken from all viewing zenith angles. We find that the regional, monthly mean biases between the nadir-only fluxes and the all-angle fluxes have decreased from -12 to $7.5 \mathrm{Wm}^{-2}$, using the existing ADMs, to between -5 and $7 \mathrm{Wm}^{-2}$ when using the ADMs described in this paper. The Antarctic-wide mean biases from sastrugi have decreased for all but one of the months we tested, with the decreases ranging from -0.02 to $-0.64 \mathrm{Wm}^{-2}$. These results are encouraging and suggest this novel method for creating ADMs is successful in accounting for the effects of sastrugi on anisotropy.

Acknowledgements. The authors would like to acknowledge Zach Eitzen and Lusheng Liang for their helpful comments and discussions about this study and manuscript. The CERES and MISR data were obtained from the NASA Langley Atmospheric Science Data Center, and the MERRA data were obtained from the Global Modeling and Assimilation Office (GMAO) and the GES DISC at NASA Goddard Space Flight Center.

Edited by: S. Schmidt

\section{References}

Carroll, J. J. and Fitch, B. W.: Effects of solar elevation and cloudiness on snow albedo at the South Pole, J. Geophys. Res., 86, 5271, doi:10.1029/jc086ic06p05271, 1981.

Corbett, J. G., Su, W., and Loeb, N. G.: Observed effects of sastrugi on CERES top-of-atmosphere clear-sky reflected shortwave flux over Antarctica, J. Geophys. Res., 117, D18104, doi:10.1029/2012jd017529, 2012.

Cox, C. and Munk, W.: Measurement of the roughness of the sea surface from photographs of the sun's glitter, J. Opt. Soc. Am., 44, 838, doi:10.1364/JOSA.44.000838, 1954.

Diner, D., Beckert, J., Reilly, T., Bruegge, C., Conel, J., Kahn, R., Martonchik, J., Ackerman, T., Davies, R., Gerstl, S., Gordon, H., 
Muller, J., Myneni, R., Sellers, P., Pinty, B., and Verstraete, M.: Multi-angle Imaging SpectroRadiometer (MISR) instrument description and experiment overview, IEEE T. Geosci. Remote, 36, 1072-1087, doi:10.1109/36.700992, 1998.

Frezzotti, M., Gandolfi, S., and Urbini, S.: Snow megadunes in Antarctica: Sedimentary structure and genesis, J. Geophys. Res., 107, 4344, doi:10.1029/2001jd000673, 2002.

Gow, A. J.: On the accumulation and seasonal stratification of snow at the South Pole, J. Glaciol., 5, 467-477, 1965.

Grenfell, T. C., Warren, S. G., and Mullen, P. C.: Reflection of solar radiation by the Antarctic snow surface at ultraviolet, visible, and near-infrared wavelengths, J. Geophys. Res., 99, 18669, doi:10.1029/94jd01484, 1994.

Hudson, S. R., Kato, S., and Warren, S. G.: Evaluating CERES angular distribution models for snow using surface reflectance observations from the East Antarctic Plateau, J. Geophys. Res., 115, D03101, doi:10.1029/2009jd012624, 2010.

Kato, S. and Loeb, N. G.: Top-of-atmosphere shortwave broadband observed radiance and estimated irradiance over polar regions from Clouds and the Earth's Radiant Energy System (CERES) instruments on Terra, J. Geophys. Res., 110, D07202, doi:10.1029/2004jd005308, 2005.

Kuchiki, K., Aoki, T., Niwano, M., Motoyoshi, H., and Iwabuchi, H.: Effect of sastrugi on snow bidirectional reflectance and its application to MODIS data, J. Geophys. Res., 116, D18110, doi:10.1029/2011jd016070, 2011.

Leroux, C. and Fily, M.: Modeling the effect of sastrugi on snow reflectance, J. Geophys. Res., 103, 25779, doi:10.1029/98je00558, 1998.

Loeb, N. G. and Manalo-Smith, N.: Top-of-Atmosphere Direct Radiative Effect of Aerosols over Global Oceans from Merged CERES and MODIS Observations, J. Climate, 18, 3506-3526, doi:10.1175/jcli3504.1, 2005.

Loeb, N. G., Kato, S., Loukachine, K., and Manalo-Smith, N.: Angular Distribution Models for Top-of-Atmosphere Radiative Flux Estimation from the Clouds and the Earth's Radiant Energy System Instrument on the Terra Satellite. Part I: Methodology, J. Atmos. Ocean. Tech., 22, 338-351, doi:10.1175/jtech1712.1, 2005.

Loeb, N. G., Sun, W., Miller, W. F., Loukachine, K., and Davies, R.: Fusion of CERES, MISR, and MODIS measurements for topof-atmosphere radiative flux validation, J. Geophys. Res., 111, D18209, doi:10.1029/2006jd007146, 2006.

Minnis, P., Sun-Mack, S., Young, D. F., Heck, P. W., Garber, D. P., Chen, Y., Spangenberg, D. A., Arduini, R. F., Trepte, Q. Z., Smith, W. L., Ayers, J. K., Gibson, S. C., Miller, W. F., Hong, G., Chakrapani, V., Takano, Y., Liou, K.-N., Xie, Y., and Yang, P.: CERES Edition-2 Cloud Property Retrievals Using TRMM VIRS and Terra and Aqua MODIS Data - Part I: Algorithms, IEEE Trans. Geosci. Remote Sensing, 49, 4374-4400, doi:10.1109/tgrs.2011.2144601, 2011.
Mondet, J. and Fily, M.: The reflectance of rough snow surfaces in Antarctica from POLDER/ADEOS remote sensing data, Geophys. Res. Lett., 26, 3477-3480, doi:10.1029/1999g1010913, 1999.

Parish, T. R. and Bromwich, D. H.: The surface windfield over the Antarctic ice sheets, Nature, 328, 51-54, doi:10.1038/328051a0, 1987.

Picard, G., Domine, F., Krinner, G., Arnaud, L., and Lefebvre, E.: Inhibition of the positive snow-albedo feedback by precipitation in interior Antarctica, Nature Climate change, 2, 795-798, doi:10.1038/nclimate1590, 2012.

Rienecker, M. M., Suarez, M. J., Gelaro, R., Todling, R., Bacmeister, J., Liu, E., Bosilovich, M. G., Schubert, S. D., Takacs, L., Kim, G.-K., Bloom, S., Chen, J., Collins, D., Conaty, A., da Silva, A., Gu, W., Joiner, J., Koster, R. D., Lucchesi, R., Molod, A., Owens, T., Pawson, S., Pegion, P., Redder, C. R., Reichle, R., Robertson, F. R., Ruddick, A. G., Sienkiewicz, M., and Woollen, J.: MERRA: NASA's Modern-Era Retrospective Analysis for Research and Applications, J. Climate, 24, 3624-3648, doi:10.1175/jcli-d-11-00015.1, 2011.

Smith, G. L.: Effects of time response on the point spread function of a scanning radiometer, Appl. Optics, 33, 7031, doi:10.1364/ao.33.007031, 1994.

Su, W., Charlock, T. P., and Rutledge, K.: Observations of reflectance distribution around sunglint from a coastal ocean platform, Appl. Optics, 41, 7369-7383, 2002.

Su, W., Corbett, J., Eitzen, Z., and Liang, L.: Next-generation angular distribution models for top-of-atmosphere radiative flux calculation from CERES instruments: methodology, Atmos. Meas. Tech., 8, 611-632, doi:10.5194/amt-8-611-2015, 2015.

Warren, S. G., Brandt, R. E., and Hinton, P. O.: Effect of surface roughness on bidirectional reflectance of Antarctic snow, J. Geophys. Res., 103, 25789, doi:10.1029/98je01898, 1998.

Wielicki, B. A., Barkstrom, B. R., Harrison, E. F., Lee, R. B., Smith, G. L., and Cooper, J. E.: Clouds and the Earth's Radiant Energy System (CERES): An Earth Observing System Experiment, B. Am. Meteorol. Soc., 77, 853-868, doi:10.1175/15200477(1996)077<0853:catere>2.0.co;2, 1996.

Wu, Y., Gong, P., Liu, Q., and Chappell, A.: Retrieving photometric properties of desert surfaces in China using the Hapke model and MISR data, Remote Sens. Environ., 113, 213-223, doi:10.1016/j.rse.2008.09.006, 2009.

Zhuravleva, T. B. and Kokhanovsky, A. A.: Influence of surface roughness on the reflective properties of snow, J. Quant. Spectrosc. Ra., 112, 1353-1368, doi:10.1016/j.jqsrt.2011.01.004, 2011. 